\title{
A FALÁCIA DO CRESCIMENTO ECONÔMICO E A QUESTÃO SOCIAL
}

João Ferreira da Silva Junior, Erika Porceli Alaniz

Universidade do Oeste Paulista - UNOESTE, Mestrado em Educação, Presidente Prudente, SP. E-mail: joaoferreira1975@bol.com.br

\section{RESUMO}

O artigo discute o quanto é contraditório o crescimento econômico capitalista e desastroso para a sociedade e a implementação da cartilha defendida pelos neoliberais, já que ambos aspectos têm proporcionado o crescimento do estado penal. Os efeitos do desenvolvimento da sociedade capitalista têm gerado desemprego estrutural e precarização do trabalho, cujos fatores têm conduzido ao crescente encarceramento em massa de indivíduos pobres. Trata-se de pesquisa bibliográfica que, além de considerar a literatura especializada sobre tema, utiliza-se a abordagem teórica de Loic Waquant para fundamentar a análise. Consideramos que o elevado número de encarcerado decorre do surgimento de um novo governo da insegurança social.

Palavras- chave: Sistema prisional. Precarização do trabalho. Controle Social.

\section{THE FALLACY OF ECONOMIC GROWTH AND SOCIAL ISSUE}

\begin{abstract}
The article discusses how much is contradictory capitalist and dismal economic growth for society and the implementation of the booklet held by the neoliberal, as both aspects have provided growth of the penal state. The effects of capitalist society development have generated structural unemployment and precarious work, whose factors have led to the growing mass incarceration of poor people. It is literature that in addition to considering the literature on topic, we use the theoretical approach of Loic Waquant to substantiate the analysis. We believe that the high number of imprisoned stems from the emergence of a new government of social insecurity.
\end{abstract}

Keywords: Prison system. Precarious work. Social control. 


\section{INTRODUÇÃO}

A precarização do trabalho, no contexto neoliberal, repercutiu na ampliação do Estado Penal, fazendo com que uma grande massa-de trabalhadores; pobres e/ou enfermos psiquiátricos fossem; para z atrás das grades, conforme expõe Foucault (2002). Essa foi a maneira que o Estado encontrou para assegurar e manter a paz social, cujo exemplo mais elucidativo são os Estados Unidos que, ao invés de terem o Estado Social, aplicam o Estado Penal.

Assim, o objetivo principal desta pesquisa é analisar o trabalho precário como um importante fator que corrobora com o Estado penal-disciplinar imposto à sociedade. $\mathrm{O}$ Estado penal-disciplinar coloca seres humanos na condição de ser objeto em que o cárcere configura-se como é um componente de uma força dissimulada ou silenciosa, servindo para obter maior eficiência e pacificação social.

A pesquisa e de cunho bibliográfico e documental, realizada, considerou a produção de LoicWacquant como eixo balizador, haja vista que apresenta uma realidade contemporânea do mundo das prisões. Além disso, procedeu-se ao levantamento das produções científicas especializadas com base em artigos, teses, dissertações, livros e capítulos de livros que tratavam da temática nas prisões.

$\mathrm{Na}$ análise documental, foram considerados os documentos oficiais do relatório do Departamento Penitenciário Nacional (Depen), de junho de 2015.

\section{A FALÁCIA DO CAPITALISMO}

Nos anos 1950 e 1960, o mundo ocidental viveu uma grande prosperidade do capitalismo, em especial nos países centrais, como os Estados Unidos, cujo período foi denominado de New Deal .Entretanto, em meados dos anos 70, surgiu a crise econômica no ocidente que, sem dúvida alguma, afetou de forma gravíssima e perversa os países mais pobres e/ou a população mais pobre dos países desenvolvidos, conduzindo muitos trabalhadores ao desemprego e ao trabalho precário, com diminuição drástica da renda familiar.

Segundo Anderson (1995, p. 10), “[...] todo o mundo capitalista avançado caiu numa longa e profunda recessão, combinando, pela primeira vez, baixas taxas de crescimento com altas taxas de inflação, mudou tudo. A partir daí as ideais neoliberais passaram a ganhar terreno."

As ideias neoliberais foram capitaneadas na teoria do livro "A Caminho da Servidão", do escritor Friedrich Hayek, escrito em 1944. Anderson (1995), ao estudar este livro comenta que o fato que mais chama a atenção é a ausência de uma racionalidade econômica, evidenciando que os conceitos, e as bases de decisões e as consequências econômicas a nível mundial e local não 
são pensados globalmente. Segundo Anderson (1995), Hayek deixa claro a sua rejeição, de qualquer espécie, ao processo de intervenção econômica, pois ninguém é capaz de prever ou calcular o que pode acontecer na economia, já que esta é um processo natural.

[...] O caráter peculiar do problema de uma ordem econômica racional é determinado precisamente pelo fato de que o conhecimento das circunstâncias das quais temos que fazer uso nunca existe de forma concentrada ou integrada, mas somente como fragmentos dispersos de um conhecimento incompleto e em geral contraditório que todos os indivíduos separadamente possuem. O problema econômico da sociedade não é, dessa forma, como alocar recursos "dados". E sim como garantir o melhor uso dos recursos conhecidos de quaisquer dos membros da sociedade, para fins cuja importância relativa somente esses indivíduos conhecem. Em resumo, o problema relevante é o da utilização do conhecimento que não é dado a ninguém em sua totalidade... (WAINRIGHT, 1998, p. 45).

Após a crise dos anos 70, houve grandes números de demissões nas indústrias, o que culminou com a implantação e aprofundamento das ideias neoliberais que preconizava uma manobra de extorsão dos direitos conquistados duramente pelos trabalhadores nas décadas anteriores. Esse processo de implantação de políticas de ajustes estruturais combinada à reestruturação produtiva nos locais de trabalho, entre outros fatores, ocasionou o enfraquecimento dos movimentos sindicais e intensificou a forma de exploração da força de trabalho por meio da flexibilização das relações de trabalho avalizada legalmente.

Antunes (2011), compara esse momento de intensa exploração da mão de obra no início do capitalismo com a economia de mercado. Ainda menciona que, com a grande crise do capitalismo no final da década de 1970, o que se tornou urgente foi livrar o Estado das amarras da intervenção do assistencialismo econômico e social, constituindo-se em uma resposta das grandes potências à crise do capital. Nesse caso, o 'Reaganismo' e 'Thatcherismo' eram uma tentativa de recompor o lucro e a produção de mercadorias, aspectos centrais para o capital.

Dessa forma, fica evidente que a economia teve um significativo crescimento nos Estados Unidos da América, Brasil e em quase todo mundo capitalista, com exceção da crise de 2009, em que houve redução do (PIB), como mostra a tabela abaixo. 
Tabela 1. CRESCIMENTO DO PIB

\begin{tabular}{l|l|l|l|l|l|l|l|l|l|l|l}
\hline $\begin{array}{l}\text { REGIÃO/ } \\
\text { PAÍS }\end{array}$ & $\mathbf{9 0 - 9 9}$ & $\mathbf{2 0 0 0}$ & $\mathbf{2 0 0 1}$ & $\mathbf{2 0 0 2}$ & $\mathbf{2 0 0 3}$ & $\mathbf{2 0 0 4}$ & $\mathbf{2 0 0 5}$ & $\mathbf{2 0 0 6}$ & $\mathbf{2 0 0 7}$ & $\mathbf{2 0 0 8}$ & $\mathbf{2 0 0 9}$ \\
\hline Mundo & 2,9 & 4,8 & 2,3 & 2,9 & 3,6 & 4,9 & 4,5 & 5,1 & 5,2 & 3,0 & 0,6 \\
\hline EUA & 3,1 & 4,1 & 1,1 & 1,8 & 2,5 & 3,6 & 3,1 & 2,7 & 2,1 & 0,4 & $-2,4$ \\
\hline Brasil & 1,7 & 4,3 & 1,3 & 2,7 & 1,1 & 5,7 & 3,2 & 4,0 & 5,7 & 5,1 & -02 \\
\hline
\end{tabular}

FONTE: PINTO, 2010.

Enquanto a economia mundial crescia, percebia-se o acentuamento do nível de pobreza em muitas nações periféricas e nas grandes economias. Por seguir a cartilha neoliberal, esses países deixaram de atender as populações mais carentes com algum tipo de benefício social, deixando- à mercê do capital, o que foi um desastre ao que se refere às políticas sociais.

Já se tornou lugar comum dizer que a classe trabalhadora vem sofrendo profundas mutações, tanto nos países centrais como no Brasil. Sabemos que um amplo contingente de força humana disponível para o trabalho, em escala global, ou se encontra exercendo trabalhos parciais, precários, temporários, ou já vivenciava a barbárie do desemprego. Mais de um bilhão de homens e mulheres padecem as vicissitudes do trabalho precarizado, instável, temporário, terceirizado, quase virtual e, dentre eles, centenas de milhões têm seu cotidiano moldado pelo desemprego estrutural. Sem ainda contabilizar os dados da Índia e China, a conta se avoluma ainda mais: (ANTUNES, 2011, p. 93).

Para Wacquant (2007), a crise do Estado providencia (assistencialista) ocasionou a erupção do Estado penal nos Estados Unidos e repercutiu, prática e ideologicamente, em outros países submetidos às reformas neoliberais. Contudo, essa desastrosa artimanha econômica imposta pelo capital levou a uma grande desigualdade social e a uma elevada concentração de renda, de modo que os $20 \%$ mais ricos da sociedade detinham $82 \%$ da riqueza a nível mundial (LOPES, SACHS e DOWBOR, 2010).

Negrão (2015), destaca que no Brasil, somente no governo Fernando Henrique Cardoso, no final dos anos 1990, os investimentos externos chegaram com mais intensidade, sendo que ao final dessa década, mais que dobrou a participação das empresas multinacionais na economia brasileira. Houve também uma intensificação sem precedente das privatizações de estatais, principalmente as mais importantes para a soberania nacional, como por exemplo, as companhias de telecomunicações.

Na perspectiva de Negrão (2015), o discurso difundido e que deu amparo para essa ação foi o fato de as empresas estatais serem improdutivas, ou seja, configurando-se como: cabide de 
emprego, endividadas, arcaicas, corruptas, não davam lucros e somente sobreviviam com a ajuda governamental. Entretanto, Negrão (2015), faz uma grande crítica a esse processo, pois a maioria das empresas estatais vendidas tiveram suas compras financiadas pelo Banco Nacional de Desenvolvimento Econômico e Social (BNDES), em outras palavras, o governo financiou a juros baixíssimos as empresas que ele próprio vendeu.

As organizações sindicais que tinham conquistados grande espaço junto aos trabalhadores foram forçadas a se reorganizarem para se manterem vivas e ativas, diante da nova realidade da precarização do trabalho e principalmente do ataque ao welfare state $^{1}$ e sua maneira de se organizar socialmente.

Diante do abandono do welfare stat, o capital neoliberal do século $\mathrm{XX}_{\text {, }}$ preferiu adotar uma política penal para com os seus cidadãos desempregados. Segundo Wacquant (2007), a punição não seria apenas pelo par "crime e castigo", mas ela anunciaria um novo modelo de governo da insegurança social, dirigindo a conduta dos homens e mulheres envolvidos no caos da desregulamentação econômica.

“Durante as décadas de 1980 e 1990, as demissões em massas tornaram-se um instrumento privilegiado de gestão financeira a curto prazo das empresas estadunidenses, de tal forma que as classes médias e gerenciais do país fizeram a amarga descoberta da insegurança do pleno emprego em plena retomada do crescimento. O retorno da prosperidade econômica nos Estados Unidos foi, portanto, construído sobre um espetacular aviltamento dos termos e das condições do emprego: entre 1980 e 1995, 41\% do pessoal "enxugado" não eram cobertos por seguro-desemprego e dois terços daqueles que encontraram emprego tiveram de aceitar uma colocação bem menos remunerada. Em 1996, 82\% dos estadunidenses se declaravam disposto a estender suas jornadas de trabalho para manter seus empregos; $71 \%$ aceitaram férias mais curtas, $53 \%$, benefícios reduzidos e $44 \%$, seus salários cortados" (WAQUANT, 2007, p. 108).

Portanto, a prisão passa a ser um espaço dos indivíduos que vivem na periferia das sociedades e, ao mesmo tempo em que se consolida como parte de uma reestruturação do campo burocrático neoliberal,-criminalizando a pobreza e suas consequências. Por fim, a prisão passa a ser um espaço por excelência da nova ordem mundial, ficando abarrotadas de indivíduos.

\section{O TRABALHO PRECÁRIO E O ENCARCERAMENTO}

O crescimento econômico das últimas duas décadas, tanto nos Estados Unidos como no Brasil, não atingiu certo grau de qualidade social e não refletiu na diminuição da criminalidade. ;

\footnotetext{
${ }^{1}$ O Estado do Bem-estar também é conhecido por sua denominação em inglês, Welfare State. Os termos servem basicamente para designar o Estado assistencial que garante padrões mínimos de educação, saúde, habitação, renda e seguridade social a todos os cidadãos. 
Os dados mostram que a taxa de encarceramento subiu a um ritmo acelerado, sem perspectiva de diminuição, porém há indícios de que haverá ainda nos próximos anos um crescimento acentuado.

Para Antunes (2011), os campos burocráticos desses países têm colaborado claramente para a desregulamentação econômica e flexibilização das leis trabalhistas, de modo que nada faz para impedir a precarização do trabalho como também contribui para que ela ocorra. Nesse contexto, a prisão emerge como estratégia eficaz de contenção do número crescente de pessoas marginalizadas. Tem-se, com isso, uma forma de criminalizar a pobreza:

"Trata-se, portanto, de uma aguda destrutividade, que no fundo é a expressão mais profunda da crise estrutural que assola a (dês) sociabilização contemporânea: destrói-se força humana que trabalha; destroçam-se os direitos sociais; brutalizam-se enormes contingentes de homens e mulheres que vivem do trabalho; torna-se predatória a relação produção/ natureza, criando-se uma enorme "sociedade dos descartáveis", que joga fora tudo que servil como "embalagem" para as mercadorias e o seu sistema, mantendo-se, entretanto, o circuito reprodutivo do capital": (ANTUNES, 2011, p. 191-).

Antunes (2011), aponta que outra característica do trabalho precarizado que levou muitos à miséria e, segundo Wacquant (2007), ao encarceramento, foram as transformações ocorridas na década de 1980. A evolução tecnológica, a robótica, a microeletrônica e a automação invadiram as fábricas, transformando o mundo do trabalho e da produção do capital.

A tabela a seguir mostra o aumento da população carcerária.

Tabela 2. Evolução Carcerária no Brasil

\begin{tabular}{c|c|c}
\hline ANO & PRESOS & CRESCIMENTO\% \\
\hline 2004 & 336,358 & 9,1 \\
\hline 2005 & 361,402 & 7,4 \\
\hline 2006 & 401,236 & 11 \\
\hline 2007 & 422,590 & 5,3 \\
\hline 2008 & 451,219 & 6,8 \\
\hline 2009 & 473,626 & 5 \\
\hline 2010 & 496,251 & 3,7 \\
\hline 2011 & 514,582 & 6,8 \\
\hline 2012 & 549,577 & $\cdots \cdots \cdots \cdots$ \\
\hline 2013 & 563,526 & $3 \ldots .$. \\
\hline
\end{tabular}

FONTE DEPEN 2015 
De acordo com Wacquant (2007), houve um crescimento significativo da economia, baseado no desemprego na precariedade profissional, juntamente com a falta de assistência social, que levou muitos indivíduos à prisão, tanto nos Estados Unidos como no Brasil, como indicado na Tabela 1.

Sabemos, que desde os trabalhos pioneiros de George Rusche e Otto Kirscheimer, confirmado por quarenta estudos empíricos em umas dezenas de sociedade capitalista, que existe no nível societário uma estreita e positiva correlação entre a deterioração do mercado de trabalho e o aumento dos efetivos presos ao passo que não existe vínculo algum comprovando entre índice de criminalidade e índice de encarceramento. (WACQUANT, 2011, p. 114).

Todas essas transformações não ocorrerão somente no campo material, mas também em cada indivíduo, afetando drasticamente a sua maneira de ser e de se situar no mundo. Por fim, segundo Antunes (2011), não há um sentimento de pertencimento de classe, mas um grande movimento racista e corporativista no mundo do trabalho, uma intensa segregação, culminando com a lógica do capital que é produzir cada vez mais para um consumo cada vez maior. Entretanto:

Wacquant (2007), Antunes (2011), Mészáros (2011), Pedroso (2007), leva-nos a pensar que essa sociedade neoliberal, ao tentar pacificar a população, devido à precarização do trabalho, banalizou a pena de prisão, porém essa grande massa de encarcerado diminui de forma significativa o índice de desemprego, configurando, podendo ser uma reserva de mão de obra para o capital ou, ainda, uma maneira de explorá-la de forma quase escrava, como cita Foucault (2007) "ao nível da mecânica", como faz algumas empresas americanas e brasileiras nas suas prisões, principalmente nos Estados Unidos onde existe uma forte indústria do encarceramento, principalmente nas unidades prisionais do sistema privado.

O capitalismo, enquanto economia de mercado, por si só, é um modelo em crise. De um lado, o progresso desse sistema social, em termos de contínua ampliação da acumulação, depende da intensificação da exploração do trabalho e do consumo desenfreado de mercadorias, muitas vezes, supérfluas à manutenção e a qualidade de vida; Por outro lado, o aumento da produtividade do trabalho não se traduz em melhores condições de vida para o conjunto da população, ao contrário, tem aumentado os números de pessoas marginalizadas e encarceradas. Pode-se dizer que nunca se encarcerou tantos sujeitos como agora, sendo que nos Estados Unidos a população carcerária passa de 2.228.424 de presos e, no Brasil há 607.731, de acordo com os 
dados do Conselho Nacional de Justiça (2015). Wacquant (2011) aponta a desordem gerada pelo desemprego em massa e pela imposição do trabalho assalariado e precário.

Ainda Wacquant (2011), nos Estados Unidos, devido à desregulamentação da economia e a precarização do trabalho, deu-se a passagem gradual do Welfare para o Workfare ${ }^{2}$, ou seja, a assistência social do Estado foi substituída por uma vigilância permanente dos indivíduos "indóceis". Na nova ordem econômica e moral, o indivíduo atendido pelo workfare deve aceitar qualquer trabalho que lhe for proposto, independente da remuneração e condições de trabalho.

"De fato seis fatores, todos eles independentes da atividade da polícia e do sistema judiciário, combinaram para reduzir fortemente a incidência dos crimes violentos nas grandes cidades dos Estados Unidos nos anos 1990. O primeiro deles foi o florescente crescimento econômico, sem precedente na história do país pela sua amplitude e duração, que gerou efetivamente empregos e garantiu rendimento a milhões de jovens até então condenados à inatividade ou "Business" ilegal, incluindo aí os guetos e os bairros onde o desemprego recuou. Mas o boom econômico não acabou com a pobreza endêmica dos bairros segregados das metrópoles estadunidenses, já que a maioria desses novos empregos eram, em sua maioria, precários e maus pagos. Mesmo quando a taxa de desemprego foi cortada em cerca da metade entre 1993 e 2000, a taxa oficial de pobreza da cidade permaneceu inalterada, em 20\%, durante a década de 1990": (Wacquant, 2011, p. 423).

Para Wacquant (2011), o crescimento econômico americano e dos países neoliberais, deuse a partir da exploração impiedosa de mão de obra com assalariamento precário e da contratação de novos empregados com direito às férias mais curtas, jornadas de trabalho maiores e corte na assistência a saúde. Assim, a prisão, serve como abrigo de pobres e negros, seria um mecanismo de regulamentação da pobreza, que, segundo Wacquant (2011p. 127), serviria "para armazenar os dejetos humanos do mercado".

\section{CONSIDERAÇÕES FINAIS}

É preciso que a sociedade mobilize-se de maneira a questionar as ideologias impostas como verdades absolutas, como algo imutável. É preciso acreditar e sair da resignação para a prática da utopia e, acima de tudo, para a busca de uma educação que almeje lançar-se para além do capital, como relata Mészáros (2008 apud Emir Sader 2008)

Em uma sociedade do capital, a educação e o trabalho se subordinam a essa dinâmica, da mesma forma que em uma sociedade em que se universialize o trabalho uma sociedade em que todos se tornem trabalhadores somente aí se

\footnotetext{
${ }^{2}$ Originalmente desenvolvido nos Estados Unidos, o workfare designa a situação em que o receptor de um beneficio social aceita trabalhar temporariamente como condição imposta pela ajuda oferecida, ou participar de treinamento profissionais e/ou cursos preparatórios para a sua inserção no trabalho que muitas vezes lhe é indicada- (SILVA, 2011, p. 09).
} 
universalizará a educação. "A 'autoeducação de iguais' e a 'autogestão da ordem social reprodutiva' não podem ser separada uma da outra"; nas palavras de Mészáros. Antes disso, a educação significa o processo de "interiorização" das condições de legitimidade do sistema que explora o trabalho como mercadoria, para induzi-los à sua aceitação passiva. Para ser outra coisa, para produzir subordinação, rebeldia, precisa redescobrir suas relações com o trabalho e com o mundo do trabalho, como o qual compartilha, entre tantas coisas, a alienação- (MÉSZÁROS 2008 apud SADER 2008, p. 7).

Mészáros (2008 apud Emir Sader 2008) convida-nos a incomodar as nossas próprias consciências, debruçar sobre a realidade do trabalho precário imposto pelo neoliberalismo à sociedade, questionar a gestão da miséria do Estado Penal e o grande sofrimento que a massa carcerária vem passando atrás das grades.

\section{REFERÊNCIAS}

ANTUNES, Roberto, Adeus ao Trabalho? 15 edições, São Paulo, Ed. Cortez.

LOIC, Wacquant, Punir os Pobres. Rio de Janeiro: Zahar, 2007.

As prisões da miséria. Trad. André Telles. Rio de Janeiro: Zahar, 2011.

Lopes, Carlos; Sachs, Ignacy; Dowbor, Ladislau (2010), Crises e oportunidades em tempos de mudança. Documento de referência para as atividades do núcleo Crises e Oportunidades no Fórum Social Mundial Temático - Bahia, Janeiro. São Paulo: Editora e Livraria Instituto Paulo Freire; Fortaleza, CE: Banco do Nordeste do Brasil.

LUDKE, Menga e ANDRÉ, Marli E. D. A. Pesquisa em educação: abordagens qualitativas. São Paulo: EPU, 1986.

MÉSZARO,ISTVAN, A Educação Para Além do Capital. São Paulo, Boi Tempo, 2008.

MINISTÉRIO DA JUSTIÇA. Departamento Penitenciário Nacional (Brasil). Síntese das Ações do Departamento Penitenciário: ano 2015. Distrito Federal: DEPEN, 2008.

PINTO, Eduardo Costa (2010). "O eixo sino-americano e a inserção externa brasileira: Antes e depois da crise". In: Inserção Internacional Brasileira: Temas de Economia Internacional. 